\title{
VOLTAGE AND POWER LOSSES CONTROL USING DISTRIBUTED GENERATION AND COMPUTATIONAL INTELLIGENCE
}

\author{
Marko Vukobratović, Predrag Marić, Željko Hederić
}

Original scientific paper

The paper analyzes the possibility of reducing active power losses in power system, constrained by regulated voltage levels, by implementing appropriate distributed generation capacity. The objectives of this paper were achieved by developing hybrid methods based on artificial neural network and genetic algorithm. Methods have been developed to determine the impact of different distributed generation power on all terminals in the observed system. The method that uses artificial neural network and genetic algorithm is applicable for radial distribution networks, and method using load flow and genetic algorithm is applicable to doubly-fed distribution network. For comparison purposes, additional method was developed that uses neural networks for the decision-making process. Data for training the neural network was obtained by power flow calculation in the DIgSILENT PowerFactory software on a part of Croatian distribution network. The same software was used as an analytical tool for checking the correctness of solutions obtained by optimization.

Keywords: artificial neural networks; distributed generation; genetic algorithm

Kontrola naponskih prilika i gubitaka snage korištenjem distribuirane proizvodnje i računalne inteligencije

Izvorni znanstveni članak U radu se analizira mogućnost smanjenja aktivnih gubitaka elektroenergetskog sustava, uz poštivanje propisanih naponskih razina, primjenom odgovarajućih kapaciteta distribuirane proizvodnje. Ciljevi ovog rada ostvareni su razvojem hibridnih metoda baziranih na umjetnim neuronskim mrežama i genetskom algoritmu. Razvijene su metode za određivanje utjecaja distribuirane proizvodnje različitih snaga na svim čvorovima u promatranom sustavu. Metoda koja koristi umjetnu neuronsku mrežu i genetski algoritam primjenjiva je za radijalne distributivne mreže, a metoda koja koristi proračun tokova snaga i genetski algoritam primjenjiva je za dvostruko napajane distributivne mreže. S ciljem usporedbe razvijena je i metoda koja koristi neuronske mreže za proces odlučivanja o najboljem rješenju. Podaci za učenje neuronske mreže dobiveni su proračunom tokova snaga u programskom alatu DIgSILENT PowerFactory i to na djelu hrvatske distributivne mreže. Isti programski alat se koristi analitički kao sredstvo provjere ispravnosti rješenja dobivenih optimizacijom.

Ključne riječi: distribuirana proizvodnja; genetski algoritam; umjetne neuronske mreže

\section{Introduction}

Distributed generation (DG) caused changes in distribution network management paradigm. Increased DG presence has made distribution network active with all new technical challenges that lay the foundations for smart-grid development.

Consumers cease to have dominant influence on the current-voltage conditions while DG production has an increasingly important impact in distribution network performance. If the local guidelines for DG implementation are taken into account, DG can improve distribution network performance by losses reduction, transmission and distribution congestion alleviation or network reliability and power quality improvement [1].

Each distribution network operating condition has its challenges needed to be overcome in order to determine DG impact in observed distribution system. System assessment can be performed if technical assumptions and measurements are available, but usually power flow analysis needs to be performed. Periodic DG production, such as those from some types of renewable energy power plants, can create additional problems and challenges for the distribution system operator which recognizes the need for advanced power distribution system management solution. In order to achieve such solution, it is crucial to develop precise mathematical optimization algorithms that could be effectively implemented in the distribution network management system. According to [2] automated distribution network, which represents prerequisite for smart-grid, must contain fast and accurate solution for power flow and current-voltage conditions control.

Respecting listed demands, artificial neural networks (ANN) are suggested as a universal solution because they have a significant ability for nonlinear problems solving in a short period of time and acceptable precision. In order to achieve full benefit of ANN it is needed for ANN to be well organized and quality made, sensible enough so it can perform a real-time optimization of the distribution network but robust enough to perform in traceable order.

ANN learning and adaptation characteristic is recognized to have a great potential in control systems because it gives them the opportunity to approximate nonlinear functions, be suited for parallel and distributed processing and model multivariable systems naturally [3]. Since ANN is based on human experience and on functional links between input and output variables, they can be used in various learning mechanisms and selforganization concepts, pattern recognition, trend determination, forecasting, function fitting etc.

The ANN can be designed, trained and fine-tuned for the purpose of control parameters assessment which can then be used for power losses minimization by DG implementation. This goal can be achieved, as presented in this paper, by using ANN as an alternative method for losses calculation presented in [4].

Optimization process implies determination of optimal DG size and location using one of the many optimization methods. Tan et al. [5] review some of the most popular optimization methods and promote computational intelligence applicability in distributed generation optimization and implementation.

El-Ela et al. [6] and Yang et al. [7] presented successful genetic algorithm (GA) usage in different types of optimization problems in the power system.

This paper proposes the optimization method based on mutual operation of ANN and GA (ANN-GA) when possible or iterative power flow calculations in 
combination with GA (PF-GA) when necessary. Necessity of power flow calculations manifests itself in the inability of fast and accurate ANN performance for specific operational scenarios. Although more computational and time demanding than ANN-GA method, PF-GA method remains acceptable in terms of requirements for performance for planning and operation of the power system. Authors evaluate another method consisting of one ANN responsible for losses estimation and another control ANN developed for decision-making process (ANN-cANN).

Overall, ANN shows good behaviour and great robustness along with satisfactory solutions if provided with quality training data and can be used in combination with GA for dynamic determination of DG size and location in some power system operation conditions.

\section{Optimization of power flow and voltage levels}

Optimization problem is usually presented as a system of objective function and constraints equations [8]:

So that: $g(x, u)=\begin{gathered}\operatorname{Min} f(x, u) \\ 0 \\ h(x, u) \leq 0\end{gathered}$,

where vector $\boldsymbol{u}$ represents control variables vector, $\boldsymbol{x}$ represents state variables vector; scalar $f(x)$ implies objective function representing optimization problem. Constraints of observed problem are given by system of equations $g(x, u)$ and inequalities $h(x, u)$. Objective function of optimal power flow is primarily given by minimization of active power losses that can be achieved by adjusting voltage levels in generator nodes within predetermined limits.

\subsection{Objective function}

Main objective function could be described as:

$F_{\text {obj }}=\operatorname{Min} P_{\text {losses }}$,

where $P_{\text {losses }}$ are losses of active power in observed system.

\subsection{Constraints}

Objective function of active power losses minimization is not suitable enough without technical constraints and correct formulation.

\subsubsection{Active power constraints}

Active power constraints are given by expression [8]:

$P_{G i}-P_{t i}-V_{i} \sum_{j=1}^{n} V_{j} \cdot\left(G_{i j} \sin \theta_{i j}+B_{i j} \sin \theta_{i j}\right)$,

where:

$i \in n-$ Number of nodes (terminals) in network
$P_{G i}$ - Active power production in the $i^{\text {th }}$ node

$P_{t i}$ - Active power consumption in the $i^{\text {th }}$ node

$\theta_{i j}-$ Angle of mutual admittance $\overline{\bar{Y}}_{i j}$ of nodes $i$ and $j$

$G_{i j}-$ mutual conductance of nodes $i$ and $j$

$B_{i j}-$ mutual susceptance of nodes $i$ and $j$

$G_{i i}$ - own conductance of node $i$

$B_{i i}-$ own susceptance of node $i$.

\subsubsection{Reactive power constraints}

Reactive power constraints are given by expression:

$Q_{G i}-Q_{t i}-V_{i} \sum_{j=1}^{n} V_{j} \cdot\left(G_{i j} \sin \theta_{i j}+B_{i j} \sin \theta_{i j}\right)$,

where:

$i \in n$ - Number of nodes in network

$Q_{G i}-$ Reactive power production in the $i^{\text {th }}$ node

$Q_{t i}$ - Reactive power consumption in the $i^{\text {th }}$ node.

\subsubsection{Voltage levels constraints}

Voltage level constraints are given by expression:

$V_{i-\min } \leq V_{i} \leq V_{i-\max }$

where:

$i \in n$ - Number of nodes in network

$V_{i \text {-min }}, V_{i-\max }-$ Voltage limitations in the $i^{\text {th }}$ node

$V_{i}-$ Voltage level in the $i^{\text {th }}$ node.

\subsubsection{Power production constraints for generator node}

Power production constraint for generator node arises from generator capability curve and technical operational limits, and can be described by expression:

$P_{G i-\min } \leq P_{G i} \leq P_{G i-\max }, i \in\left\{N_{p v}, N_{0}\right\}$,

where:

$P_{G i \text {-min }}, P_{G i-\max }-$ Power production limits in the $i^{\text {th }}$ node $N_{p v}$ - Number of PV nodes

$N_{0}-$ DG node.

During the optimization process, voltage levels and loss of stability risk have to be taken into account along with main goal, the power losses reduction, since the objective function formed with the purpose of active power losses reduction only could provide the technically unsustainable solution without predicting sufficient amount of reactive power reserves in case of one or more elements failing in observed system.

\section{Artificial neural network design and implementation}

Aforementioned optimization problem causes for convenient solution development. Complexity and nonlinear interdependences of observed optimization problem cause difficulty in providing the fast and correct solution using classical (exact) optimization techniques 
such as linear programming, interior point method or mixed integer programming [3].

Instead of exact techniques, new methods for complex nonlinear problems solving is imposed by using ANN and other computational intelligence methods.

Different types of ANN will perform differently and provide very distinct solutions so typology and structure determination is crucial for ANN proper behaviour. Feedforward neural networks represent most common type of ANN, but occasionally observed mathematical problem demands radial basis function (RBF) network usage or Kohonen self-organizing network usage. Also, some uncommon types, such as bi-directional RNN, recurrent neural network (RNN) or stochastic neural network could be used, usually assisted by another computational intelligence method. When there is an easy way to generate significant amount of input and target examples and when there is a clear solution for a seemingly complex problem which can be described by flow chart, back-propagation (BP) ANN can be used. Calculation of losses is such a problem and ANN can successfully replace calculation process.

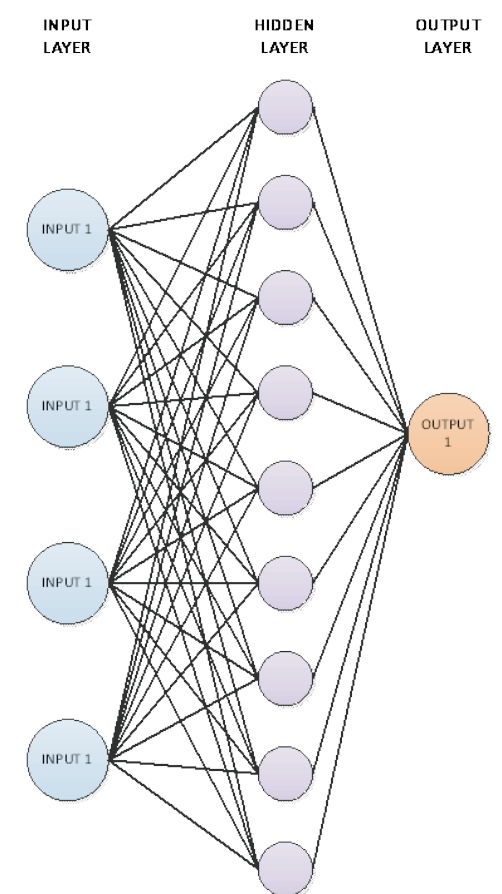

Figure 1 Structure of Artificial Neural Network

ANN consists of neuron layers which can be organized as required by observed problem. BP ANN has an obligatory input layer, a mandatory output layer, and at least one hidden layer which comprises the largest number of neurons. Numbers of hidden layers are theoretically infinite but usually one to four layers is adequate to solve any kind of complex problems [9].

Each layer has to be fully connected to the vicinal layer by every neuron, as shown in Fig. 1. Connections between neurons can include weight factors which determine their behaviour.

Relationship between input and output values of multi-layer ANN can be represented as [10]:

$$
y=f\left(\sum_{i=0}^{N-1} W_{i} \cdot X_{i}(t)-k\right)
$$

where:

$y$ - Output value

$X_{i}$ - Input value

$W_{i}$ - weighting factor

$k$ - threshold value

$N$ - layer number

$f$ - nonlinear function.

Learning process, a variant of the Delta Rule [3], is next step in ANN design since it evaluates the efficacy of ANN creation. Learning starts with determining the relationships between layers and neurons by error assessment. Error represents the difference between the target examples and ANN actual outputs. Based on errors the weighting factor and biases are changed accordingly. Weight factors are changed according to training data and based on expression [10]:

$$
\Delta_{P} W_{j i}=n\left(t_{p j}-o_{p j}\right) i_{p i}=n \delta_{p j} i_{p j}
$$

where:

$n$ - learning rate

$t_{p j}-j$ component of the $p^{\text {th }}$ target output

$o_{p j}-j$ component of the $p^{\text {th }}$ computed output

$i_{p i}-i$ component of the $p^{\text {th }}$ input pattern

$\delta_{p j}-$ error of target and computed output.

Correct design and successful testing in training process cause for ANN to provide reasonable outputs for every new set of inputs. The layers and neurons in that case behave as equation variables and connections between them represent nonlinear interdependencies. Usually the precision of ANN outputs is increased as the training data increases. For the purpose of this paper ANN is designed with the aim to substitute analytical approach of losses calculation presented in papers $[4,11,12]$ and trained by simulation data as described later in this paper.

Acharya et al. [4] presented analytical formulation based on exact loss formula, and Wang et al. [11] and Gözel et al. [12] presented loss sensitivity formulation which enabled power loss minimization by an analytical method without usage of complex calculations involving admittance matrix, inverse of admittance matrix or Jacobian matrix. ANN design and implementation in this paper continues line of research, but instead of presented analytical approach, the development of ANN passes to the computer intelligence approach. Once designed and trained correctly, ANN disposes sufficient opportunities to substitute analytical approach, thus relieving computing requirements and reducing execution time.

\subsection{Neural network training}

As mentioned before, larger training data increases the ANN implementation success rate. Sufficient quantity of training data is determined by ANN behaviour; when the ANN outputs are in accordance with calculation 
outputs the desired behaviour may be declared as achieved.

The input training data for the purpose of this paper consists of: DG active power production varying from 0 $\mathrm{kW}$, representing no production, to $1 \mathrm{MW}$ representing full production, by $10 \mathrm{~kW}$ step; injected current from corresponding DG production given in $\mathrm{kA}$; voltage level on low-voltage side when DG is active and the voltage level on medium-voltage side when DG is active, given in per-unit (p.u.) values.

Target training data for the ANN learning are total feeder losses for each observed scenario. Designed ANN has four input neurons and one output neuron connected with one hidden layer consisting of 15 neurons. The training of ANN is performed by Levenberg-Marquardt algorithm for nonlinear least squares problems. Calculations necessary for training data generation, power losses, voltages and currents are performed using DIgSILENT PowerFactory software. The results of observed case are introduced into tables.

Power losses evaluation and identification is necessary due to the lifetime impact of the equipment included and due to power system economic operation [7]. ANN training process performance is shown in Fig. 2.

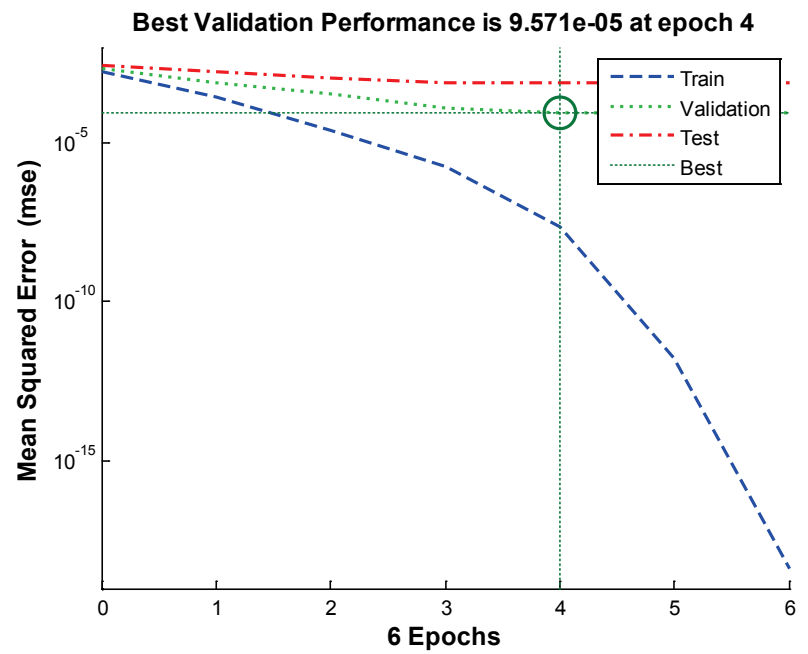

Figure 2 Performance of ANN training

Distribution network observed and modelled is based on a part of Croatian Grid Company distribution network. Nominal voltages of observed network are $35(20) \mathrm{kV}$ and $0,4 \mathrm{kV}$, consisting of 48 nodes, 23 transformers and 25 different low-voltage loads. The observed distribution network is connected to the parent network on two sides, two major junctions in reality, but usual operating conditions are never doubly-fed due to operator technical conditions. If network is fully loaded, the voltage values drop under 0,85 p.u. as shown in Fig. 3.

Total installed peak power in the observed system is 2,59 MVA with an average power factor of 0,9. Peak loaded network with load diversity factor of one, as defined as worst case scenario, is considered as an operating condition studied by the research for the purpose of this paper. Training data for ANN simulation and performance evaluation of the proposed ANN-GA method has been conducted for time-independent loads and time-independent generation, of equal values in every observed scenario and method performance.

DG types differ by their energy source and timedependent production [13]. For the purpose of this research, DG is modelled as a PQ node, with a power factor of $\cos \varphi=1$, and power that can vary by technical limitations from $100 \mathrm{~kW}$ to $1350 \mathrm{~kW}$. The reason for such modelling is based on a real type of synchronous Stamford generator widely used in DG applications in Croatia with nominal power of $1350 \mathrm{~kW}$ and $1500 \mathrm{~min}^{-1}$.

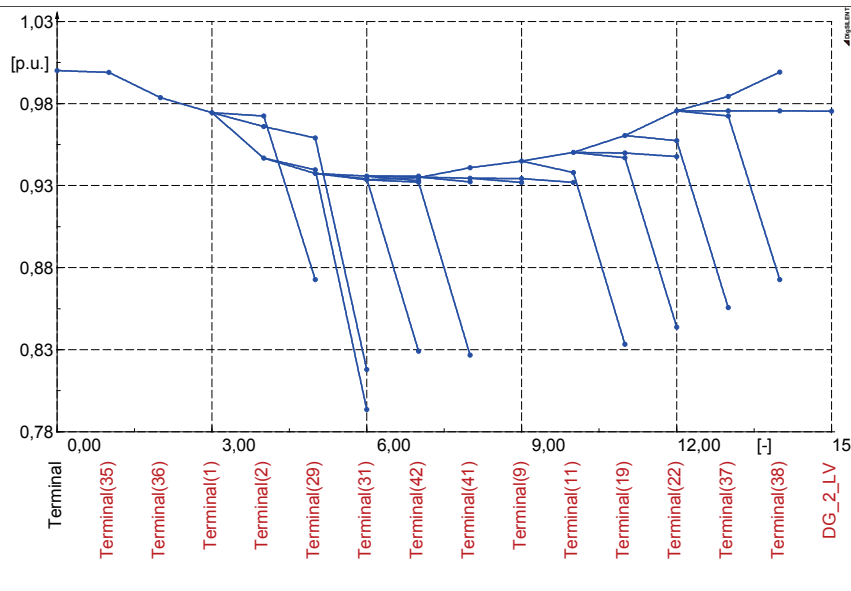

Figure 3 Voltage drop in fully loaded distribution network

Normal operating conditions for observed distribution network are not fully loaded terminals and it is never doubly-fed, but it is important to notice what happens to voltage values in that possible operation scenario. One possible solution for voltage values increase is planning of an adequate distributed generation on the convenient terminal. In this case, the continuous electric power production would be an adequate type as the stable source the network operator could rely on.

\section{Simulation and results}

ANN results in correspondence with DIgSILENT PowerFactory calculation results are shown in Fig. 5.

Calculation results provided by DIgSILENT PowerFactory power flow calculation are considered actual operating values since aforementioned software has proven its reliability and precision.

ANN is firstly tested on one terminal, randomly selected for DG implementation. Performance of the ANN, results correspondence, is acceptably good; the comparison of losses results given by DIgSILENT PowerFactory and by ANN after proper training shows that ANN manages to determine the valid value of power losses thus successfully replacing expressions proposed by $[4,11,12]$. Voltage levels are respected in such a way that the DG power is limited to those values that do not cause voltage level exceeding. DG power limitations are obtained by previous power flow calculation. Results generated by ANN are generally matching the results provided by DIgSILENT PowerFactory calculations, except in the case of $400 \mathrm{~kW}$ DG production, where significant result difference is evident. This is consequence of insufficient sensitivity to nonlinear changes of the ANN and of specific distribution network 
topology and operation. Identified problem is solved and ANN behaviour is improved by managing the neuron connections weight factors, biases between neurons and hidden neurons number or hidden layers number. Not all mentioned activities are necessary, number of neurons could be reduced or some neurons could be designated as not achievable by increasing weight factors.

After fine-tuning of ANN losses estimation performs appropriate when applied in radial, single-fed, networks, but sometimes remits false results when applied to doubly-fed distribution networks.

Since most rural areas of Croatian distribution network are single-fed, ANN-GA method may be usable in real-life conditions. For doubly-fed networks PF-GA method is developed which consumes more computing power and performance time but provides erroneous results risk-free environment.

Optimal solution finding by DG implementation is conducted by appropriate node and DG size assessment. This could be done analytically by comparing the results and finding the lowest values or by using optimization algorithms. In this paper GA is used for optimization purposes.

\subsection{Optimal solution finding}

Once the ANN is designed and successfully tested, the optimal solution needs to be found. Optimization process could be described as decision-making process with goal of finding global best solution. In order for that process to perform correctly, optimization algorithm has to be quality designed. Increasing research efforts have been directed at applying various types of decisionmaking ANNs to optimization problems. Opinions about ANN performance vary from considering ANN highly effective for unstructured decision-making to emphasized reservations towards ANN decision-making by proposing other methods. The ANN for decision making and optimal solution finding is not primarily used in this paper, although authors developed and used such with the aim of testing the performance and comparison of results.
Singh et al. [14] successfully developed GA for optimum allocation of distributed generation based on technical and economic constraints. GA was also successfully used in noteworthy papers by Biswas et al. [1], El-Ela et al. [6], López-Lezama et al. [15] and Harrison et al. [16].

In this paper GA is used in a specific manner, partially different from previous authors, since the starting population is created by the same active power for every individual in population, where individuals differ by connected terminals. This approach lines with the usage of particle swarm optimization (PSO) technique and provides good basis for future research.

The arrangement of the population and individual coding is shown in Fig. 4 [9].

Another approach of GA coding could employ each terminal as a population, where individuals of that population could be represented with different active power. In both coding approaches the result will be the same; individual that best meets the fitness function will be named as the best individual.

Coding of DG and has to be a fixed-length bit string in order for GA to function properly [17]. Each position in a string is presumed to represent a particular feature of an individual in a population, DG power and location in this case.

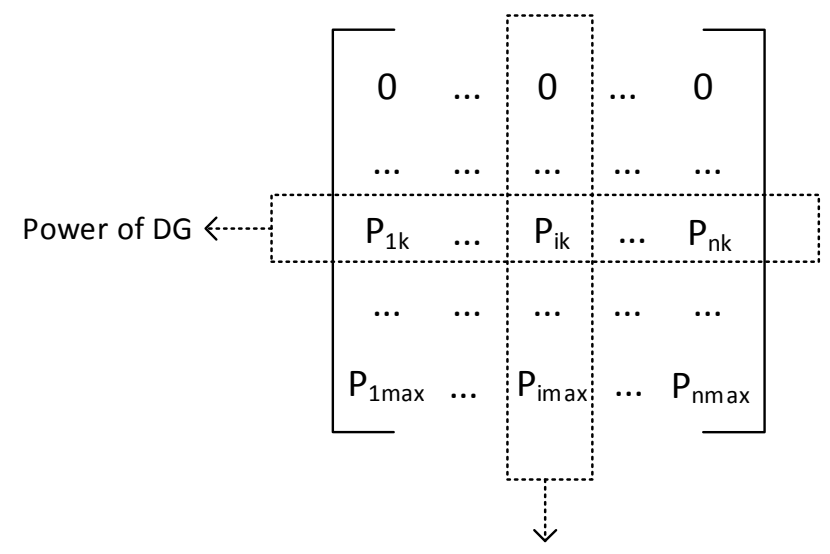

Individual on i-th terminal

Figure 4 Coding of population and individual in GA

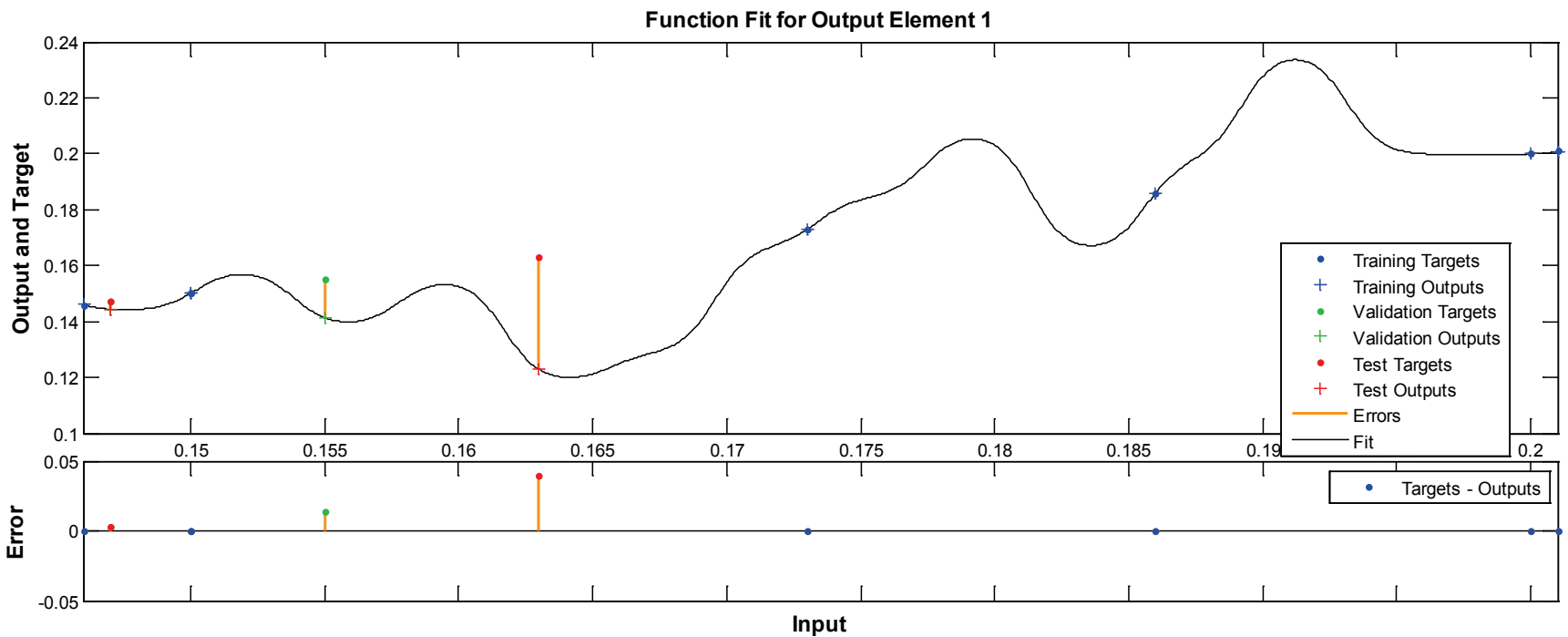

Figure 5 Fitting of the ANN 
Table 1 Results of simulation in DIgSILENT and by ANN

\begin{tabular}{|c|c|c|c|c|c|}
\hline $\begin{array}{c}\text { DG power } \\
\text { production } / \mathrm{kW}\end{array}$ & Injected current / kA & $\begin{array}{l}\text { Low voltage } \\
\text { terminal / p.u. }\end{array}$ & $\begin{array}{l}\text { High voltage } \\
\text { terminal / p.u. }\end{array}$ & $\begin{array}{c}\text { Active power losses } \\
\text { / MW } \\
\text { DIgSILENT }\end{array}$ & $\begin{array}{c}\text { Active power losses } \\
\text { / MW } \\
\text { ANN }\end{array}$ \\
\hline 0,00 & 0,00 & 0,93 & 0,93 & 0,200 & 0,19998 \\
\hline 100,00 & 0,92 & 1,00 & 0,99 & 0,201 & 0,20061 \\
\hline 200,00 & 0,84 & 1,00 & 0,99 & 0,186 & 0,18600 \\
\hline 300,00 & 0,80 & 1,00 & 0,99 & 0,173 & 0,17300 \\
\hline 400,00 & 0,81 & 1,00 & 0,99 & 0,163 & 0,12291 \\
\hline 500,00 & 0,85 & 1,00 & 0,99 & 0,155 & 0,14141 \\
\hline 600,00 & 0,94 & 1,00 & 0,99 & 0,150 & 0,15008 \\
\hline 700,00 & 1,04 & 1,00 & 0,99 & 0,147 & 0,14441 \\
\hline 800,00 & 1,17 & 1,00 & 1,00 & 0,146 & 0,14607 \\
\hline 900,00 & 1,30 & 1,00 & 1,00 & 0,147 & 0,14441 \\
\hline 1000,00 & 1,44 & 1,00 & 1,00 & 0,150 & 0,15008 \\
\hline
\end{tabular}

Feature evaluation is determined by values stored in particular positions in coding [9]. Advanced approach to problem coding and formulation, such as tree encoding, could be applied if results are not satisfactory. For the purpose of this paper binary encoding was performed and satisfactory results obtained.

As mentioned, ANN-cANN method was developed for comparison purposes in order to evaluate control ANN performance in decision-making process. Algorithm of ANN-cANN method is shown in Fig. 6.

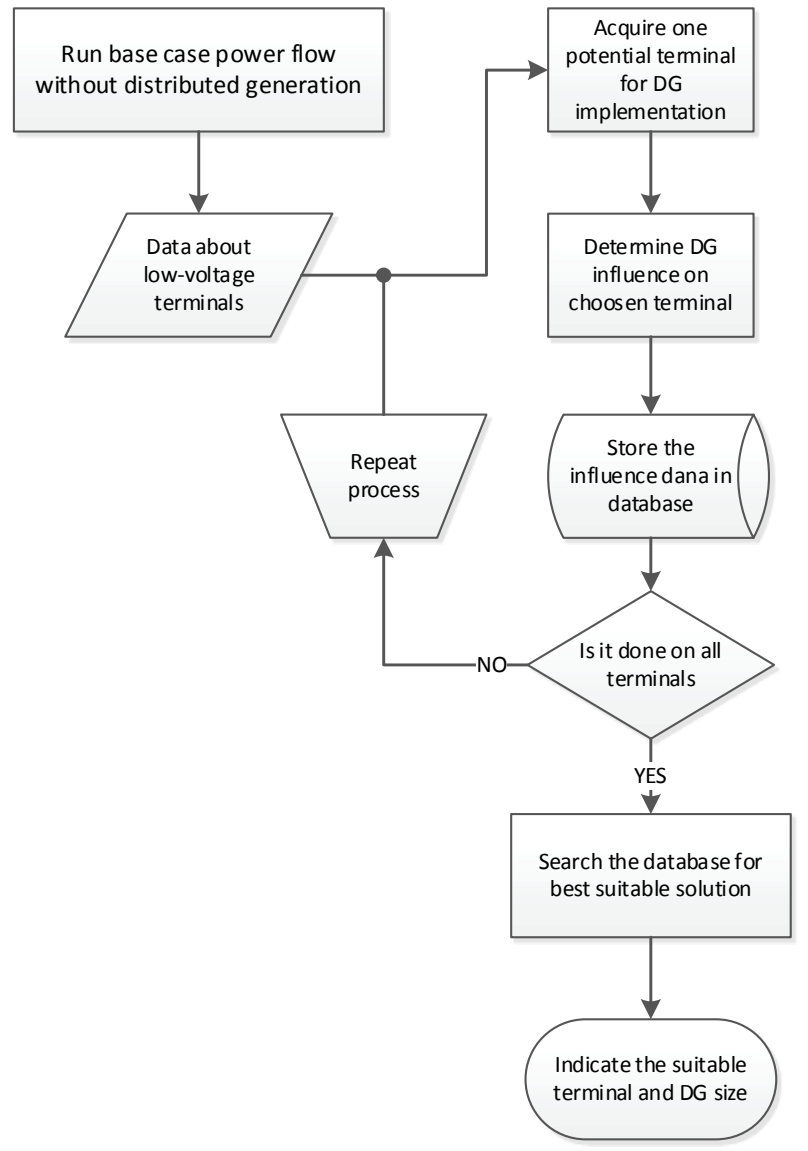

Figure 6 Algorithm for finding the best solution by ANN-cANN method

Separate-type ANN for the determination of the best suitable terminal and DG size for the voltage value regulation and active power losses minimization is designed and set as a control ANN for the primary ANN, the one for estimating the active power losses. cANN is based on pattern recognition in pattern vector consisting of estimated losses. If made parallel, two ANNs could show malfunction so the best classification of those ANNs is to have one in control and data evaluation and one in calculation process.

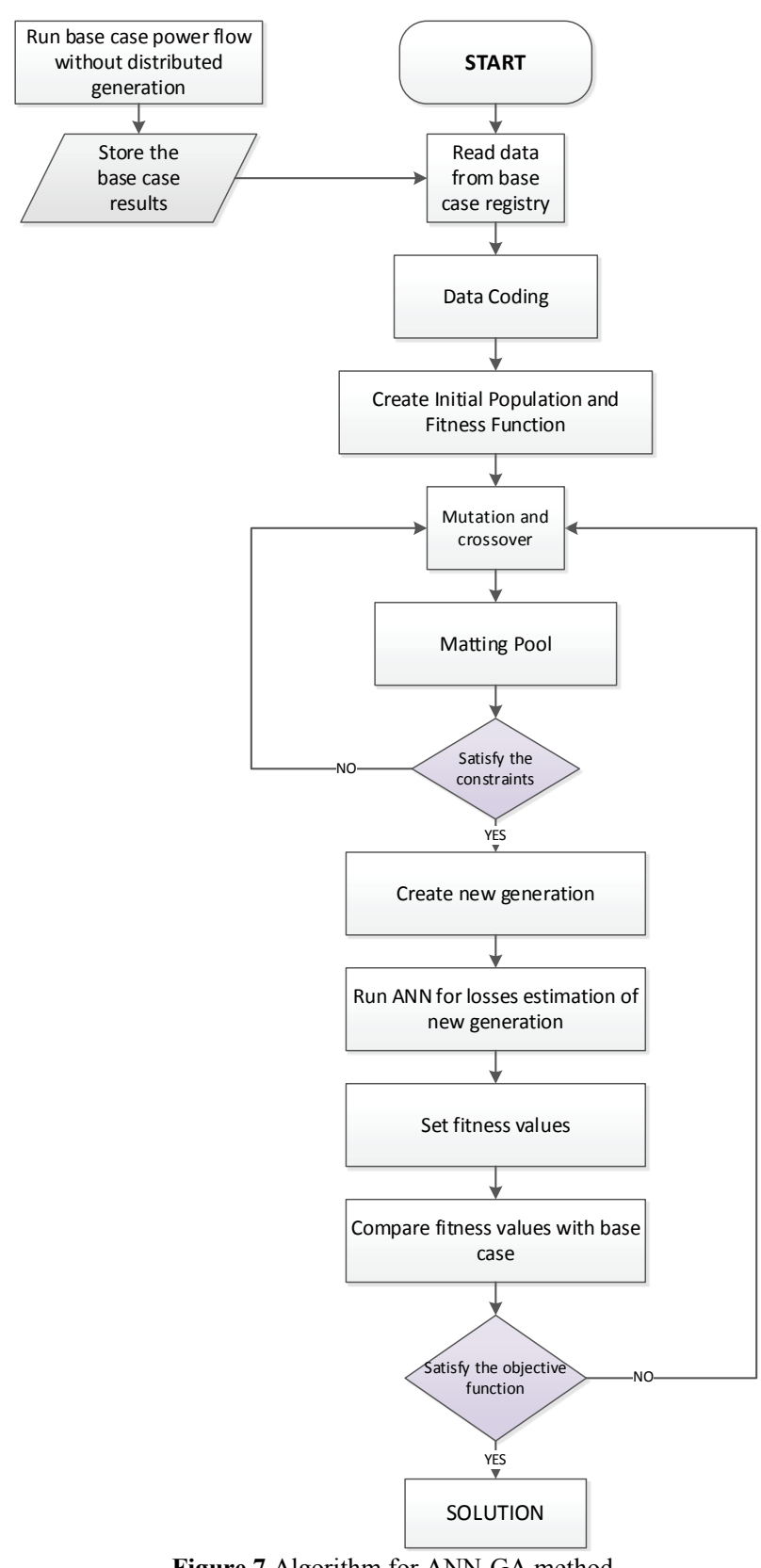

Figure 7 Algorithm for ANN-GA method 
Results obtained from additional cANN were compared with results obtained by GA. Inefficient and sometimes improper behaviour of cANN is concluded, mostly because of local minimum pinning. Therefore, the approach that uses the ANN for losses estimation, thereby bypassing analytical approach, and GA for optimization purposes shows better implementation and usefulness.

Immediately after drawing conclusion that ANN-cANN method does not result in the desired effect, the said method was abandoned and replaced with ANNGA and PF-GA methods respectively.

ANN-GA and PF-GA methods are almost identical with the significant difference in how the impact of distributed generation is evaluated. In ANN-GA method, ANN is used for losses estimation instead of losses calculation and GA is used for optimization purposes. PF-GA method differs from aforementioned in the calculation of losses; in PF-GA method values for losses are obtained by power-flow calculations instead of ANN estimation. Proposed method algorithm is shown in Fig. 7.

Power flow calculations are performed in MATLAB using MATPOWER package.

After conducting all simulations and implemented calculations using ANN-GA method in an observed radial distribution network, the optimal power of distributed generation proved to be $700 \mathrm{~kW}$ on terminal 8 , located in the middle of the distribution feeder. Control analysis by analytical approach was established using DIgSILENT PowerFactory software which led to the best suitable solution; $800 \mathrm{~kW} \mathrm{DG}$ on the terminal 8 . The difference in results is a consequence of ANN imperfection so for future work the more accurate ANN will be developed. When $700 \mathrm{~kW}$ DG is placed on the terminal 8, the voltage characteristic is improved as shown in Fig. 8

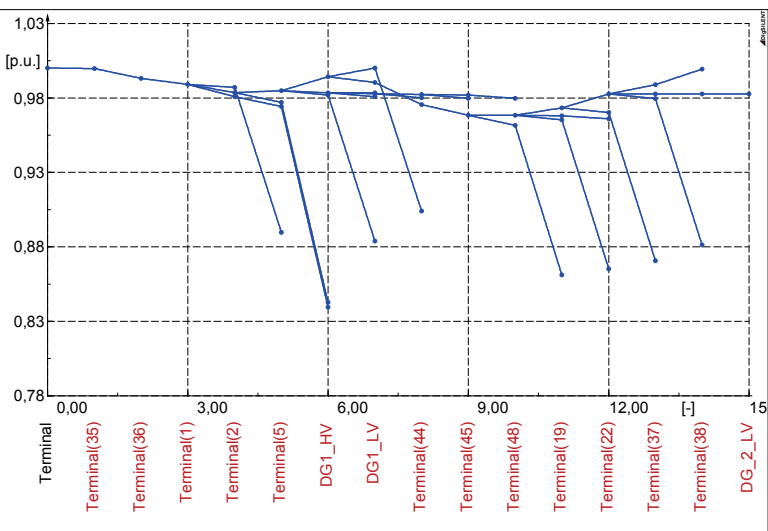

Figure 8 Voltage levels with $800 \mathrm{~kW}$ DG on Terminal 8

In order to evaluate third PF-GA method, the same optimization process is conducted. Optimization result is in case of PF-GA method similar to the expected known best result.

With a view to further verify the proposed methods, authors tested the ANN-GA and PF-GA algorithms on multiple network models. MATPOWER package was used for power flow calculations and for purpose of multiple power system modelling. In case of PF-GA usage it is not necessary to perform constraints satisfaction since power flow calculation is based on constraint equations.

In any given case both ANN-GA and PF-GA method took acceptably short execution time regarding short-term management of distribution network so it can be concluded that the proposed methods could prove usefulness of future challenges in the power system.

\section{Conclusion}

Distributed Generation (DG) is increasingly represented in electrical distribution network so the influence of DG needs to be properly evaluated and rated. Misjudging the effects of DG influence could be hazardous for power system. The fast and the correct solution for the DG influence on distribution network evaluating can be provided using Artificial Neural Networks (ANN) because of their ability to solve nonlinear mathematical problems quickly with great precision. Back-propagation ANN is designed for estimating the active power losses in the electric power system, thus replacing analytical approach. ANN is trained by power flow calculation results provided by DIgSILENT PowerFactory software. Optimization process was concluded using genetic algorithm (GA).

Algorithm comprising ANN for losses estimation and GA for optimization (ANN-GA) proved usefulness in radial distribution networks. For doubly-fed networks additional algorithm consisting of MATPOWER power flow calculations and GA for optimization (PF-GA) was developed. In order to investigate the ANN possibility in decision making process, additional method was developed consisting of ANN for losses estimation, and control ANN for decision making (ANN-cANN), but did not show consistency and traceability of results. Optimization results were controlled for correctness analytically by DIgSILENT PowerFactory software.

ANN-GA method and PF-GA method were tested on multiple distribution network models and in every observed scenario both methods prove usefulness regarding execution time and optimization accuracy thereby indicating the direction for developing power system management solutions.

\section{$6 \quad$ References}

[1] Biswas, S.; Goswami, S. K.; Chatterjee, A. Optimum distributed generation placement with voltage sag effect minimization. // Energy Conversion and Management. 53(2012), pp. 163-174. DOI: 10.1016/j.enconman.2011.08.020

[2] Swarup, K. S.; Subash, P. S. Neural network approach to voltage and reactive power control in power systems. // in Intelligent Sensing and Information Processing, 2005.

[3] Sumathi, S.; Surekha, P. Computational Intelligence Paradigm - Theory and applications using Matlab, CRC Press, Taylor \& Francis Group, 2010.

[4] Acharya, N.; Mahat, P.; Mithulananthan, N. An analytical approach for DG allocation in primary distribution network. // Electrical power and Energy Systems. 28(2006), pp. 669678. DOI: 10.1016/j.jiepes.2006.02.013

[5] Tan, W.-S.; Mohammad, H. Y.; Majid, S.; Rahman, H. A. Optimal distributed renewable generation planning: A review of different approaches. // Renewable and Sustainable Energy Reviews. 18, (2013), pp. 626-645. DOI: 10.1016/j.rser.2012.10.039 
[6] El-Ela, A. A.; Allam, S.; Shatla, M. Maximal optimal benefits of distributed generation using genetic algorithms. // Electric Power System Research. 80(2010), pp. 869-877. DOI: 10.1016/j.epsr.2009.12.021

[7] Yang, N.-C.; Chen, T.-H. Evaluation of maximum allowable capacity of distributed generations connected to a distribution grid by dual genetic algorithm. // Energy and Buildings. 43(2011), pp. 3044-3052. DOI: 10.1016/j.enbuild.2011.07.025

[8] Vukobratović, M.; Marić, P.; Hederić, Ž. Optimization Method for Control of Voltage Level and Active Power Losses Based on Optimal Distributed Generation Placement Using Artificial Neural Networks and Genetic Algorithms. // Journal of Energy Technology. 6, 4(2013), pp. 11-30.

[9] Vukobratović, M.; Hederić, Ž.; Hadžiselimović, M. Optimal Distributed Generation Placement in Distribution Network. // in Proceedings EnergyCon 2014 - IEEE International Energy Conference, Red Hook, NY 12571 USA, 2014.

[10] Byeong-Gi, K.; Dae-Seok, R. Optimal voltage regulation method for distribution systems with disitributed generation systems using artificial neural networks. // Journal of Electrical Engineeirng \& Technology. 8, 4(2013), pp. 712718. DOI: $10.5370 / J E E T .2013 .8 .4 .712$

[11] Wang, C.; Nehrir, H. M. Analytical Approches for Optimal Placement of Distributed Generation Sources in Power Systems. // IEEE Transactions on Power Systems. 19, 4(2004), pp. 2068-2076. DOI: 10.1109/TPWRS.2004.836189

[12] Gözel, T.; Hocaoglu, H. M. An analytical method for the sizing and siting of distributed generators in radial systems. // Electric Power System Research. 79(2009), pp. 912-918. DOI: 10.1016/j.epsr.2008.12.007

[13] Soares, J.; Silva, M.; Sousa, T.; Vale, Z.; Morais, H. Distributed energy resource short-term scheduling using Signaled Particle Swarm Optimization. // Energy. 42(2012), pp. 466-476. DOI: 10.1016/j.energy.2012.03.022

[14] Singh, R. K.; Goswami, S. K. Optimum allocation of distributed generations based on nodal pricing for profit, loss reduction, and voltage improvement including voltage rise issue. // Electric Power and Energy Systems. 32(2010), pp. 637-644. DOI: 10.1016/j.jijepes.2009.11.021

[15] López-Lezama, J. M.; Contreras, J.; Padilha-Feltrin, A. Location and contract pricing of distributed generation using a genetic algorithm. // Electrical Power and Energy Systems. 36, (2012), pp. 117-126. DOl: 10.1016/j.jjepes.2011.10.032

[16] Harrison, G. P.; Piccolo, A.; Siano, P.; Wallace, R. Hybrid GA and OPF evaluation of network capacity for distributed generation connections. // Electric Power Systems Research. 78, (2008), pp. 392-398. DOI: 10.1016/j.epsr.2007.03.008

[17] Vukobratović, M.; Nikolovski, S.; Marić, P. Improving the Conditions in a Radial Distribution Feeder by Implementing Distributed Generation. // International Journal of Electrical and Computer Engineering Systems. 6, 1(2015), pp. 1-7.

\section{Authors' addresses}

Marko Vukobratović, M. Eng.

J. J. Strossmayer University of Osijek,

Faculty of Electrical Engineering, Computer Science and Information Technology Osijek, Power System Department, Kneza Trpimira 2b, 31000 Osijek, Croatia E-mail: marko.vukobratovic@etfos.hr

Doc. Predrag Marić, Dr. Sc.

J. J. Strossmayer University of Osijek,

Faculty of Electrical Engineering, Computer Science and Information Technology Osijek, Power System Department, Kneza Trpimira 2b, 31000 Osijek, Croatia

E-mail: predrag.maric@etfos.hr

Prof. Željko Hederić, Dr. Sc.

J. J. Strossmayer University of Osijek,

Faculty of Electrical Engineering, Computer Science and Information Technology Osijek, Power System Department, Kneza Trpimira 2b, 31000 Osijek, Croatia

E-mail: zeljko.hederic@etfos.hr 